\title{
INFLUENCIA DE LA EDAD DEL CALLO EN LA INDUCCIÓN DE SUSPENSIONES CELULARES DE CAFETO ${ }^{1}$
}

\author{
María Esther González-Vega $a^{2}$, María Margarita Hernández-Espinosa², Annia Hernández-Rodríguez ${ }^{3}$
}

\begin{abstract}
RESUMEN
Influencia de la edad del callo en la inducción de suspensiones celulares de cafeto. Esta investigación se desarrolló en el Departamento de Genética y Mejoramiento de Plantas del Instituto Nacional de Ciencias Agrícolas (INCA), provincia La Habana, Cuba, durante el período de 2002 al 2004, con el objetivo de evaluar el comportamiento de suspensiones celulares de tres genotipos de Coffea canephora $\mathrm{P}$. var. Robusta, para ello se procedió a estudiar la edad del callo más eficiente para el establecimiento del cultivo en medio líquido, para lo cual se evaluaron callos de 15, 21, 28, 35, 42, 49 y 56 días de cultivo. También se estudiaron diferentes medios de cultivos para la multiplicación celular, MMC-1 con $0,2 \mathrm{mg} / \mathrm{l}$ de Kinetina y $0,5 \mathrm{mg} / \mathrm{l}$ de 2,4-D, empleado como medio control y el medio MMC-2 donde el 2,4-D fue sustituido por $0,7 \mathrm{mg} / \mathrm{l}$ de un extracto auxínico de origen bacteriano. Se determinaron los efectos de estos factores en la velocidad de desagregación, la coloración de la suspensión, así como en la concentración de células totales y meristemáticas. Se encontró que las suspensiones a partir de callos de 28 y 35 días de cultivo en medio sólido, presentaron mejor respuesta, dado el mayor número de células, velocidad de desagregación y adecuada coloración de la suspensión, destacándose los callos de estas edades como los más favorables para la inducción del cultivo en medio líquido, a partir de los genotipos estudiados. Se obtuvieron mejores resultados con el medio de multiplicación celular MMC-2.
\end{abstract}

Palabras clave: Coffea canephora, Robusta, extracto bacteriano, 2,4-D, células meristemáticas

\begin{abstract}
Effect of callus age on the induction of coffee cell suspension cultures. The investigation was developed in the Department of Crop Genetics and Breeding from the National Institute of Agricultural Sciences (INCA), La Habana, Cuba, from 2002 to 2004, to evaluate the behavior of cells suspensions of three Coffea canephora P. var. Robusta genotypes. Seven callus ages (15, 21, 28, 35, 42, 49 and 56 days) were evaluated to find the age most appropriate for culture establishment in liquid medium. Different culture media were evaluated for cell multiplication, MMC-1 with $0.2 \mathrm{mg} / \mathrm{l}$ Kinetin and $0.5 \mathrm{mg} / \mathrm{l}$ 2,4-D (control) and MMC-2 where 2,4-D was substituted by $0.7 \mathrm{mg} / \mathrm{l}$ of an auxin extract of bacterial origin. The effects of these factors on the time of callus disaggregation, coloration of the cell suspension, and concentration of total and meristematic cells were determined. The optimum age of callus for the induction of cell suspension was 28-35 days, given the higher number of cells, disaggregation speed and good coloration of the cell suspension. The best results were obtained with the medium MMC-2 for cell multiplication.
\end{abstract}

Key words: Coffea canephora, Robusta, bacterial extract, 2,4-D, meristematic cells.

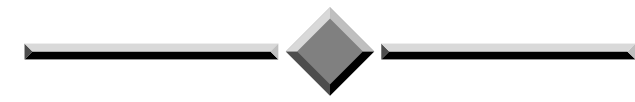

\footnotetext{
1 Recibido: 4 de abril, 2008. Aceptado: 18 de noviembre, 2010. Este trabajo formó parte de una Tesis de Doctorado en Ciencias Agrícolas. Especialidad Biotecnología Vegetal, perteneciente al Instituto Nacional de Ciencias Agrícolas. Cuba.

2 Departamento de Genética y Mejoramiento de las Plantas. Instituto Nacional de Ciencias Agrícolas. Gaveta Postal 1, San José de Las Lajas. La Habana.Cuba. esther@inca.edu.cu,marylago00@yahoo.com

3 Departamento de Microbiología. Facultad de Biología. Universidad de La Habana. Calle 25 \# 455 entre J e I. Plaza de la Revolución, Ciudad Habana. Cuba.
} 


\section{INTRODUCCIÓN}

El café es uno de los productos agrícolas más importantes en el mercado mundial (Ricketts et al. 2004). Constituye una fuente principal de divisas para naciones en vías de desarrollo que lo cultivan como África, América Latina y Asia (FAO 2000). La tradición cafetalera de Cuba data de 1748. Al introducir la especie Coffea arabica (1833), Cuba llegó a ser el primer exportador mundial del preciado rubro (Sánchez 2006).

La micropropagación de plantas es una de las técnicas de mayor aplicación en la industria biotecnológica actual (Klimaszewska et al. 2007); sin embargo, su expansión está condicionada al estudio de los factores que regulan dicho proceso. En el cultivo de células en suspensión que no es más que el cultivo en el que las células aisladas y agregados celulares crecen y se multiplican suspendidos en un medio líquido, es importante el conocimiento de la influencia de los factores físicos y químicos. Este es un método muy utilizado para la selección de mutantes, uso de fermentadores en la embriogénesis somática, semilla artificial y en la producción de metabolitos secundarios tales como antibióticos, saborizantes, proteínas, bioinsecticidas, enzimas para fines farmacológicos y alimenticios, ya que los medios líquidos ofrecen condiciones más homogéneas, haciendo los nutrientes más accesibles al tejido. También elimina el agente gelificante, que es uno de los insumos utilizados más costosos (Salazar y Hoyos 2007). Varios investigadores han empleado esta técnica en el cultivo de $C$. arabica y Coffea canephora con sorprendentes resultados (Zamarripa et al. 1991, Montes et al. 1995, Van Boxtel y Berthouly 1996, Santana et al. 1998, Cevallos 2000, Barry et al. 2002, De Feria et al. 2003).

En el cafeto, la producción a gran escala de individuos deseados a través del cultivo in vitro, ya sea en medio sólido o a través del cultivo en medio líquido ha abierto nuevas perspectivas a la multiplicación vegetativa de algunas especies, aspecto significativo en el cultivo de C. canephora var. Robusta, caracterizada por su autoincompatibilidad (Montagnon et al. 1998). Estos métodos de propagación sin el empleo de la semilla, ofrecen enormes ventajas para esta especie de alogamia estricta, debido a la posibilidad de reproducción uniforme de los genotipos seleccionados (Zamarripa 1993).

También es conocido que este tipo de propagación asexual mantiene el vigor del material inicial lo que no es posible usando otro tipo de técnicas no vegetativas como la propagación por semillas, lo cual resulta de gran interés para materiales mejorados para la siembra en generación filial F1, donde el aprovechamiento del vigor híbrido o heterosis constituye una necesidad.

En este sentido la determinación del momento adecuado para el establecimiento de la suspensión celular a partir de callos cultivados en medio sólido resulta importante, a fin de garantizar la presencia del tipo celular más favorable y considerando que este puede variar con relación a las características genéticas de la fuente de los explantes (Santana et al. 1998).

De aquí que el presente trabajo se realizó con el objetivo de estudiar el efecto de la edad del callo durante la etapa de establecimiento de la suspensión celular, como fase previa a la inducción y regeneración de embriones somáticos de tres genotipos promisorios de C. canephora P. var. Robusta.

\section{MATERIALES Y MÉTODOS}

La presente investigación se desarrolló en el Departamento de Genética y Mejoramiento de Plantas del Instituto Nacional de Ciencias Agrícolas (INCA), ubicado en el municipio de San José de las Lajas, provincia La Habana, durante el período de 2002 al 2004.

Se utilizaron tres genotipos promisorios: M-229, K-234 y M-28 (Figura 1) del Banco de germoplasma de la Estación Central de Investigaciones de Café y Cacao (ECICC).

La variedad Robusta se caracteriza por la alta potencialidad productiva que ha alcanzado, representando rendimientos promedios entre 1,5 y 2,0 t/ha de café comercial (Díaz et al. 2002), así como por la manifestación de resistencia a ciertas plagas y enfermedades, su resistencia a la sequía, su rusticidad y por la posibilidad de propiciar híbridos de interés entre ésta y las variedades de C. arabica (López et al. 1993).

Para estudiar la influencia de la edad del callo en la inducción de suspensiones celulares de cafeto se utilizaron hojas procedentes de los genotipos M229, K-234 y M-28, a partir de éstas se seleccionaron explantes foliares de $1 \mathrm{~cm}^{2}$ de longitud. Para la toma de las muestras foliares, la desinfección y disección se siguió la metodología establecida para este cultivo en estudios precedentes (Santana et al. 1998).

Para la inducción de callo se utilizó el medio MFA-3 (González et al. 2007), constituido por las sales minerales del medio de cultivo MS (Murashige 

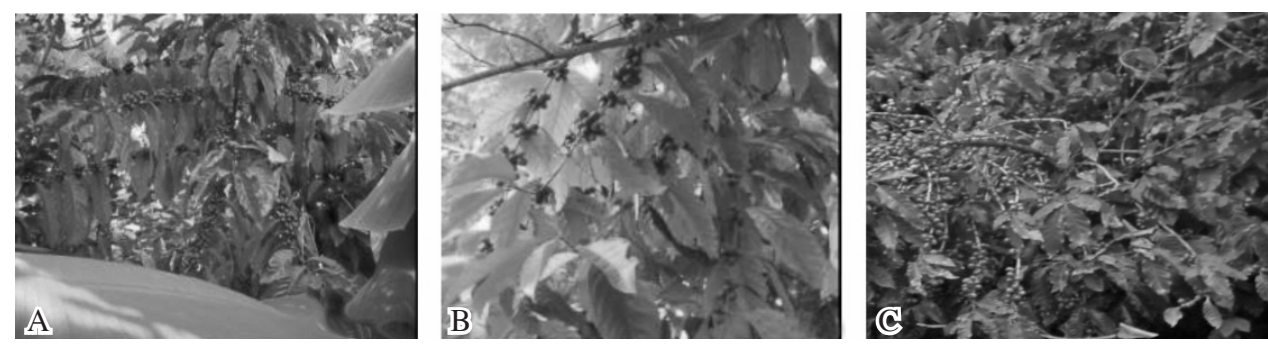

Figura 1. Estructura externa de las plantas de C. canephora var. Robusta. A- Genotipo M-229, B- Genotipo K-234 y C- Genotipo M-28. La Habana, Cuba, 2004.

y Skoog 1962) (10 ml/l), con mioinositol $(100 \mathrm{mg} / \mathrm{l})$, vitaminas de Morell (4 mg/l), cisteína-HCl $(25 \mathrm{mg} / \mathrm{l})$, sacarosa $(30 \mathrm{~g} / \mathrm{l})$ y como reguladores del crecimiento $2,0 \mathrm{mg} / \mathrm{l}$ de Kinetina y $0,7 \mathrm{mg} / \mathrm{l}$ de un extracto auxínico obtenido a partir de un biopreparado bacteriano (Hernández 2002), obtenido a partir de metabolitos activos de una cepa nativa de Burkholderia cepacia, aislada de la rizosfera del cultivo del maíz. Entre los componentes del mismo se destacan auxinas, citoquininas, ácido salić́lico, sideróforos y alcaloides quinilosidínicos de naturaleza antibiótica. Como agente gelificante se utilizó gelrite $(2 \mathrm{~g} / \mathrm{l})$. El pH fue ajustado a 5,7 y la esterilización se realizó en autoclave a $121^{\circ} \mathrm{C}$, durante 15 minutos y $1,2 \mathrm{~kg} / \mathrm{cm}^{2}$. Los subcultivos se realizaron cada 21 días, tomando como referencia resultados precedentes obtenidos al evaluar las curvas de crecimiento celular para cada genotipo.

\section{Determinación de la edad óptima del callo}

Para el establecimiento de la suspensión celular, los callos objeto de estudio se tomaron a los 15, 21, $28,35,42,49$ y 56 días de cultivo. Una vez alcanzadas las edades prefijadas, los callos de coloración blancocremosa y consistencia friable, fueron transferidos a los medios de multiplicación celular, de igual composición que el medio de formación de callo MFA-3, excepto los reguladores del crecimiento que en este caso fueron en MMC-1: 0,2 mg/l de Kinetina y 0,5 $\mathrm{mg} / \mathrm{l}$ de 2,4-D empleado como medio control (Montes et al. 1995) y en el medio MMC-2, el 2,4-D fue sustituido por $0,7 \mathrm{mg} / \mathrm{l}$ del extracto auxínico de origen bacteriano.

Se utilizaron erlenmeyers de $50 \mathrm{ml}$ de capacidad, contentivos de $15 \mathrm{ml}$ de medio de cultivo, los que fueron colocados en zaranda orbital a $110 \mathrm{rpm}, 27 \pm$ $1^{\circ} \mathrm{C}$ y fotoperíodo de 16 horas luz/8 oscuridad con una intensidad lumínica entre 4000 y 5000 luxes. Se empleó una densidad de inóculo inicial (DI) igual a diez gramos de masa fresca por litro (gMF/l).

Posterior a los 21 días de cultivo las suspensiones se pasaron por un filtro de gasa $(1500 \mu \mathrm{m}) \mathrm{y}$ se subcultivaron en $25 \mathrm{ml}$ del mismo medio en que se encontraban transfiriéndose a erlenmeyers de $100 \mathrm{ml}$ de capacidad. En este caso la DI fue de $3 \mathrm{gMF} / 1$ (Montes et al. 1995).

Pasados 21 días en este medio de cultivo, las suspensiones se transfirieron a erlenmeyers de 250 $\mathrm{ml}$ de capacidad con $70 \mathrm{ml}$ de los medios MMC-1 o MMC-2, según correspondiera. Para evaluar el efecto de los diferentes tratamientos (edad del callo x medio de cultivo), se inocularon cinco erlenmeyers por cada genotipo con una DI igual a $3 \mathrm{gMF} / 1$. En todos los casos, los subcultivos se realizaron cada 21 días.

A los 15 días se evaluó la velocidad de desagregación (días), que consistió en la evaluación visual de los días transcurridos para la liberación de las células que formaban parte del callo, debido al movimiento del medio de cultivo liquido. Además se evaluó la coloración de la suspensión (de blanco cremoso a carmelita) de acuerdo a la escala 1, establecida a tal efecto:

Escala 1: Coloración de la suspensión

BC- Blanco-cremoso

Cr- Crema

CC- Carmelita claro

A los 60 días de subcultivadas las suspensiones, se evaluó la concentración de células totales y de células meristemáticas (No. de cél $/ \mathrm{ml}$ ), en diez muestras por tratamiento, a través del conteo celular en cámara de Fuch Rosentals (García et al. 1996). 
En el montaje del experimento se utilizó un diseño Completamente Aleatorizado con cinco repeticiones por tratamiento y tres periodos en el tiempo.

\section{Análisis estadísticos}

A todas las variables se les comprobó su normalidad por el método de Shapiro y Francia (Shapiro y Francia 1972). Para el análisis estadístico, los datos originales de las variables expresadas en $\%$ se transformaron mediante la fórmula $\operatorname{arcsen} \sqrt{\%}$ y los datos de conteos celulares a través de la fórmula Log x. A los valores de las diferentes variables se les realizó un análisis de varianza bifactorial, utilizando el procesador estadístico Start Ver 4.10 (INCA. START 1998). Se definió el factor A- Medio de cultivo con los niveles MMC-1 y MMC-2 y como factor B- Edad del callo con los niveles, 15, 21, 28, 35, 42, 49 y 56 días de cultivo.

En los casos en que se observaron diferencias significativas, se aplicó la prueba de Rangos Múltiples de Duncan al 5\%, para la comparación de las medias, utilizando el programa STATGRAPHICS (1999).

\section{RESULTADOS Y DISCUSIÓN}

Al analizar el efecto del medio de cultivo y la edad del callo sobre los valores de células totales, se detectó interacción significativa (Cuadro 1). En el genotipo M-229, los callos de 28 y 35 días cultivados en medio MMC-2, con $0,7 \mathrm{mg} / \mathrm{l}$ del extracto auxínico indujeron la mayor concentración, con valores de 30 y 29 × $10^{4} \mathrm{cel} / \mathrm{ml}$, respectivamente, los que difirieron de los obtenidos en el resto de las combinaciones, le siguieron callos de este genotipo e igual período de cultivo, inoculados en MMC-1. El resto de los tratamientos mostró una tendencia a la disminución de la concentración con el aumento de la edad del callo.

En el genotipo K-234, se obtuvo un comportamiento similar al observado en el genotipo M-229, las variantes de callos de 28 y 35 días en el medio MMC2 , mostraron las concentraciones más elevadas con 30 y $31 \times 10^{4} \mathrm{cel} / \mathrm{ml}$, respectivamente, seguidas por los valores alcanzados con los callos de 21 y 42 días en el medio MMC-1 y callos de 28 y 35 días en el medio MMC-2, que presentaron valores de $19 \times 10^{4} \mathrm{cel} / \mathrm{ml}$, observándose una mayor respuesta al cultivo en medio MMC-2 para este genotipo. El resto de las variantes mostró valores de concentración celular que no superaron el $17 \times 10^{4} \mathrm{cel} / \mathrm{ml}$.

En el genotipo M-28, el mayor número de células se logró solo con callos de 35 días de cultivo en el medio MMC-2, al parecer, los callos de este genotipo requirieron de un tiempo más prolongado en medio de formación de callos para expresar mayor proliferación

Cuadro 1. Efecto de la edad del callo en el número de células totales por $\mathrm{ml}$ (x 104) en C. canephora var. Robusta a los 60 días de cultivo. La Habana, Cuba, 2004.

\begin{tabular}{ccccccc}
\hline \multirow{2}{*}{$\begin{array}{c}\text { Edad callo } \\
\text { (días) }\end{array}$} & \multicolumn{2}{c}{ M-229 } & \multicolumn{2}{c}{ K-234 } & \multicolumn{2}{c}{ M-28 } \\
\cline { 2 - 7 } & MMC-1 & MMC-2 & MMC-1 & MMC-2 & MMC-1 & MMC-2 \\
\hline 15 & $14,1 \mathrm{f}$ & $16,4 \mathrm{de}$ & $13,4 \mathrm{e}$ & $15,6 \mathrm{~d}$ & $13,8 \mathrm{~g}$ & $17,1 \mathrm{e}$ \\
21 & $18,3 \mathrm{~cd}$ & $19,1 \mathrm{c}$ & $17,9 \mathrm{c}$ & $19,2 \mathrm{~b}$ & $12,3 \mathrm{~h}$ & $18,4 \mathrm{~d}$ \\
28 & $23,9 \mathrm{~b}$ & $30,1 \mathrm{a}$ & $19,9 \mathrm{~b}$ & $30,5 \mathrm{a}$ & $18,1 \mathrm{~d}$ & $22,1 \mathrm{~b}$ \\
35 & $25,3 \mathrm{~b}$ & $29,8 \mathrm{a}$ & $19,7 \mathrm{~b}$ & $31,7 \mathrm{a}$ & $15,3 \mathrm{f}$ & $22,3 \mathrm{a}$ \\
42 & $17,4 \mathrm{~d}$ & $18,7 \mathrm{c}$ & $18,3 \mathrm{c}$ & $19,5 \mathrm{~b}$ & $15,4 \mathrm{f}$ & $17,2 \mathrm{e}$ \\
49 & $14,2 \mathrm{f}$ & $16,4 \mathrm{de}$ & $13,4 \mathrm{e}$ & $17,8 \mathrm{c}$ & $13,7 \mathrm{~g}$ & $11,7 \mathrm{~h}$ \\
56 & $13,1 \mathrm{~g}$ & $15,9 \mathrm{e}$ & $12,1 \mathrm{f}$ & $15,2 \mathrm{~d}$ & $12,1 \mathrm{~h}$ & $19,8 \mathrm{c}$ \\
\hline ES $\bar{x}( \pm)$ & \multicolumn{3}{c}{$0,311^{* *}$} \\
\hline
\end{tabular}

Medias con letras comunes no difieren estadísticamente, según Prueba de Rangos Múltiples de Duncan para p $<0,05$.

** significativo para $\mathrm{p}<0,01$ 
celular en medio líquido, lo que pudo estar asociado a las propias características de este material.

Los resultados mostraron que en las condiciones evaluadas el momento más adecuado para la selección del callo y su inoculación en medio líquido, para la multiplicación celular, estuvo comprendido entre los 28 y 35 días posteriores a su cultivo en medio sólido en los genotipos M-229 y K-234, mientras que los resultados en M-28 fueron más favorables con callos de 35 días, en todos los casos inoculados en el medio MMC2, demostrándose la superioridad del medio con el extracto auxínico del biopreparado, en sustitución del 2,4-D, lo que corroboró la efectividad de este nuevo bioproducto para la multiplicación celular, llegándose a alcanzar valores superiores a $30 \times 10^{4} \mathrm{cel} / \mathrm{ml}$.

Este comportamiento demostró que con el empleo del extracto auxínico se logró una mayor activación del crecimiento de las suspensiones celulares en los tres genotipos, lo que pudiera deberse a los aspectos antes expuestos, con relación a los materiales evaluados y sus requerimientos hormonales.

La determinación del momento adecuado para el establecimiento de la suspensión celular a partir de los callos cultivados en medio sólido resultó importante, teniendo en cuenta que éste puede variar con relación a las características genéticas de la fuente de los explantes. Existen especies dentro de un mismo género y especialmente variedades en una misma especie que pueden diferir en cuanto a la facilidad para responder a las diferentes etapas de cultivo in vitro, jugando un papel esencial el tiempo de cultivo (Santana et al. 1998).

Los resultados de la concentración de células meristemáticas en las suspensiones de los genotipos en estudio se reflejan en el Cuadro 2.

Se obtuvieron valores que, similares a la variable analizada anteriormente, difirieron significativamente en dependencia de la edad del callo y el medio de cultivo a partir del cual se estableció la suspensión, obteniéndose los mayores porcentajes al emplear callos de 28 y 35 días y el medio MMC-2 en los genotipos M-229 y K-234, así como callos de 35 días y este mismo medio en el genotipo M-28, estos valores oscilaron entre 60,7 y $88,3 \%$.

Los resultados obtenidos fueron diferentes a los alcanzados con el tratamiento control (MMC-1) y las edades anteriormente mencionadas, comportamiento que fue observado para los tres genotipos.

El genotipo M-28, se caracterizó por presentar los menores porcentajes para las edades y medios de cultivo evaluados, aunque resultó favorecido con callos de 35 días y el medio MMC-2, coincidiendo con el comportamiento de los genotipos M-229 y K-234.

De forma general, a los 60 días de cultivo se observó un alto porcentaje de células meristemáticas para las condiciones mencionadas, éstas se caracterizaron por presentar una forma casi esférica, núcleo grande, alto

Cuadro 2. Efecto de la edad del callo en el número de células meristemáticas en suspensiones de C. canephora var. Robusta (\%) a los 60 días de cultivo. La Habana, Cuba, 2004.

\begin{tabular}{ccccccc}
\hline \multirow{2}{*}{$\begin{array}{c}\text { Edad callo } \\
\text { (días) }\end{array}$} & \multicolumn{2}{c}{ M-229 } & \multicolumn{2}{c}{ K-234 } & \multicolumn{2}{c}{ M-28 } \\
\cline { 2 - 7 } & MMC-1 & MMC-2 & MMC-1 & MMC-2 & MMC-1 & MMC-2 \\
\hline 15 & $41,2 \mathrm{j}$ & $49,3 \mathrm{~h}$ & $41,3 \mathrm{~h}$ & $49,6 \mathrm{fg}$ & $11,5 \mathrm{i}$ & $19,3 \mathrm{~h}$ \\
21 & $45,3 \mathrm{i}$ & $59,3 \mathrm{~g}$ & $51,5 \mathrm{f}$ & $53,8 \mathrm{e}$ & $18,9 \mathrm{~h}$ & $29,5 \mathrm{~g}$ \\
28 & $78,2 \mathrm{c}$ & $87,7 \mathrm{a}$ & $73,4 \mathrm{~b}$ & $83,4 \mathrm{a}$ & $42,9 \mathrm{c}$ & $44,6 \mathrm{~b}$ \\
35 & $71,5 \mathrm{f}$ & $88,3 \mathrm{a}$ & $72,6 \mathrm{~b}$ & $82,8 \mathrm{a}$ & $33,7 \mathrm{e}$ & $60,7 \mathrm{a}$ \\
42 & $77,1 \mathrm{~d}$ & $80,9 \mathrm{~b}$ & $65,6 \mathrm{~d}$ & $69,3 \mathrm{c}$ & $31,8 \mathrm{f}$ & $43,2 \mathrm{c}$ \\
49 & $41,5 \mathrm{j}$ & $73,4 \mathrm{e}$ & $50,9 \mathrm{f}$ & $51,2 \mathrm{f}$ & $30,9 \mathrm{f}$ & $43,4 \mathrm{c}$ \\
56 & $40,8 \mathrm{j}$ & $71,3 \mathrm{f}$ & $48,7 \mathrm{~g}$ & $50,8 \mathrm{f}$ & $28,8 \mathrm{~g}$ & $41,3 \mathrm{~d}$ \\
\hline ES $\bar{x}( \pm)$ & \multicolumn{3}{c}{$0,012^{* *}$} & \multicolumn{2}{c}{$0,171^{* *}$} & \multicolumn{2}{c}{$0,041^{* *}$} \\
\hline
\end{tabular}

Medias con letras comunes no difieren estadísticamente, según Prueba de Rangos Múltiples de Duncan para $\mathrm{p}<0,05$.

** significativo para $\mathrm{p}<0,01$. 
contenido citoplasmático y alta capacidad de división; lo que constituyó un importante indicador del potencial embriogénico de la suspensión, ya que generalmente estas células forman parte de la suspensión junto a células parenquimatosas y agregados proembriogénicos, los que a su vez dan lugar a los embriones somáticos (Jong et al. 1993). De los resultados mostrados y lo antes expuesto, se infiere que la capacidad embriogénica de los genotipos M-229 y K-234 en medio líquido, superó a la del genotipo M-28, tanto con el empleo del extracto auxínico como con el 2,4-D.

En este sentido, Cevallos (2000) al evaluar la composición celular en suspensiones de otro genotipo de C. canephora a los 60 días de cultivo, obtuvo que el mayor porcentaje de células correspondió al tipo meristemáticas (61\%), siendo este valor superado por los resultados obtenidos en el presente estudio para algunas de las combinaciones de medio de multiplicación celular y edad del callo evaluadas.

Estos resultados reflejan el efecto favorable del extracto auxínico y las ventajas de garantizar el establecimiento de la suspensión celular a partir de callos con edades adecuadas, a fin de garantizar la presencia del tipo celular más favorable. Otros autores, en condiciones de bioreactores y para la especie $C$. arabica, han informado la presencia de $90,85 \%$ de células meristemáticas y $9,15 \%$ de células parenquimáticas (De Feria et al. 2003).
La velocidad de desagregación presentó mejor comportamiento en el genotipo M-229 a partir de callos de 28 y 35 días de cultivo y las dos variantes de medio de cultivo evaluadas (Cuadro 3), mostrando valores promedio de seis días para la obtención de suspensiones celulares.

Sin embargo, las combinaciones de medio de cultivo y las diferentes edades de los callos evaluadas, en el genotipo K-234, mostraron valores muy similares que oscilaron alrededor de los once días, difiriendo solo las velocidades alcanzadas para las suspensiones obtenidas a partir de callos de 49 y 56 días de cultivo en el medio MMC-1 y MMC-2, cuyos valores fueron de doce y trece días, respectivamente, comportamiento que pudiera atribuirse a la consistencia esponjosa de los callos, que dificultó la separación de las células que formaban parte de la masa callogénica.

El genotipo M-28 presentó un comportamiento diferente, siendo diez días la velocidad máxima de desagregación obtenida en callos de 28 a 42 días, sin observarse diferencias entre ellos. En el resto de las combinaciones la velocidad de desagregación osciló entre once y trece días. Al evaluar el comportamiento de suspensiones celulares de la especie C. arabica establecidas a partir de callos provenientes de material de campo y de 25 días de formados, se obtuvieron velocidades de desagregación de siete a ocho días; sin embargo, callos de 25 días pero obtenidos a partir de

Cuadro 3. Velocidad de desagregación de la masa callogénica en genotipos de C. canephora var. Robusta a los 15 días de cultivo. La Habana, Cuba, 2004.

\begin{tabular}{ccccccc}
\hline \multirow{2}{*}{$\begin{array}{c}\text { Edad callo } \\
\text { (días) }\end{array}$} & \multicolumn{2}{c}{ M-229 } & \multicolumn{2}{c}{ K-234 } & \multicolumn{2}{c}{ M-28 } \\
\cline { 2 - 7 } & MMC-1 & MMC-2 & MMC-1 & MMC-2 & MMC-1 & MMC-2 \\
\hline 15 & $12,66 \mathrm{a} *$ & $12,31 \mathrm{a}$ & $11,82 \mathrm{c}$ & $11,85 \mathrm{c}$ & $12,01 \mathrm{~b}$ & $12,15 \mathrm{~b}$ \\
21 & $12,61 \mathrm{a}$ & $12,47 \mathrm{a}$ & $11,74 \mathrm{c}$ & $11,72 \mathrm{c}$ & $11,35 \mathrm{c}$ & $11,42 \mathrm{c}$ \\
28 & $6,61 \mathrm{e}$ & $6,50 \mathrm{e}$ & $11,80 \mathrm{c}$ & $11,82 \mathrm{c}$ & $10,46 \mathrm{~d}$ & $10,41 \mathrm{~d}$ \\
35 & $6,33 \mathrm{e}$ & $6,37 \mathrm{e}$ & $11,77 \mathrm{c}$ & $11,89 \mathrm{c}$ & $10,37 \mathrm{~d}$ & $10,23 \mathrm{~d}$ \\
42 & $7,83 \mathrm{~d}$ & $7,71 \mathrm{~d}$ & $11,68 \mathrm{c}$ & $11,71 \mathrm{c}$ & $10,00 \mathrm{~d}$ & $10,01 \mathrm{~d}$ \\
49 & $10,88 \mathrm{~b}$ & $10,75 \mathrm{~b}$ & $12,81 \mathrm{~b}$ & $12,91 \mathrm{~b}$ & $11,03 \mathrm{c}$ & $11,09 \mathrm{c}$ \\
56 & $9,61 \mathrm{c}$ & $9,59 \mathrm{c}$ & $13,81 \mathrm{a}$ & $13,85 \mathrm{a}$ & $13,83 \mathrm{a}$ & $13,88 \mathrm{a}$ \\
\hline ES $\bar{x}( \pm)$ & \multicolumn{2}{c}{$0,481^{*}$} & \multicolumn{2}{c}{$0,032^{* *}$} & \multicolumn{2}{c}{$0,041^{* *}$} \\
\hline
\end{tabular}

\footnotetext{
*Medias con letras comunes no difieren estadísticamente, según Prueba de Rangos Múltiples de Duncan para $\mathrm{p}<0,05$

** significativo para $\mathrm{p}<0,01$.
} 
Cuadro 4. Coloración de las suspensiones celulares de C. canephora var. Robusta con relación a la edad del callo a los 15 días de cultivo. La Habana, Cuba, 2004.

\begin{tabular}{lccccccc}
\hline Genotipo & \multicolumn{7}{c}{ Edad (días) } \\
\cline { 2 - 8 } & $\mathbf{1 5}$ & $\mathbf{2 1}$ & $\mathbf{2 8}$ & $\mathbf{3 5}$ & $\mathbf{4 2}$ & $\mathbf{4 9}$ & $\mathbf{5 6}$ \\
\hline M-229 & Blanco cremoso & Blanco cremoso & Blanco cremoso & Blanco cremoso & Carmelita claro & Carmelita claro & Carmelita claro \\
K-234 & Crema & Crema & Crema & Crema & Carmelita claro & Carmelita claro & Carmelita claro \\
M-28 & Crema & Crema & Crema & Crema & Carmelita oscuro & Carmelita oscuro Carmelita oscuro \\
\hline
\end{tabular}

explantes de vitroplantas, expresaron la desagregación a los cuatro días (Cevallos 1995).

Los resultados mostraron que la respuesta a este indicador está en correspondencia con las características del callo, en cuanto a edad de cultivo, procedencia y calidad del callo, a partir del cual se induce el cultivo en medio líquido.

$\mathrm{Al}$ analizar las características de las suspensiones celulares desde el punto de vista de su apariencia morfológica, se observó que el color de la suspensión varió para los genotipos M-229, K-234 y M-28 (Cuadro 4).

Las suspensiones presentaron una tonalidad cremosa desde el principio y tornándose carmelita claro en el genotipo K-234, al igual que en el M-229, a partir de los 42 días y carmelita oscuro en el M-28. Los resultados indicaron que para los genotipos evaluados las edades comprendidas entre 15 y 35 días arrojaron resultados favorables con relación a la morfología de las células en suspensión por el color de la misma, lo que se corresponde con el comportamiento obtenido en los demás indicadores evaluados.

Se ha informado que en estudios relacionados con $C$. canephora var. Robusta, a pesar de lograrse un alto contenido de embriones en suspensiones de color carmelita oscuro, éstos no llegaron a convertir en plántulas sino que continuaron en las etapas de desarrollo embrionario: globular, acorazonado y torpedo (Montes et al. 1995). Demostrándose la importancia de este aspecto con relación al color de la suspensión, ya que puede constituir un marcador visual de gran utilidad práctica para identificar callos y suspensiones de alto potencial embriogénico.

Las suspensiones a partir de callos de 28 y 35 días de cultivo en medio sólido, presentaron mejor respuesta, dado el mayor número de células, velocidad de desagregación y aspectos cualitativos de la suspensión, destacándose los callos de estas edades como los más favorables para la inducción del cultivo en medio líquido, a partir de los genotipos estudiados. Los resultados más favorables se obtuvieron con el medio de multiplicación celular MMC-2.

\section{LITERATURA CITADA}

Barry-Etienne, D; Bertrand, B; Schlonvoigt, A; Etienne, H. 2002. The morphological variability within a population of coffee somatic embryos produced in a bioreactor affects the regeneration and the development of plants in the nursery. Plant Cell, Tissue and Organ Culture 68:153-162.

Cevallos, M. 1995. Embriogénesis somática en Coffea arabica L.var. 9723: Estudio morfobioquímico de la callogénesis en medio sólido. Caracterización de suspensiones celulares. Trabajo de Diploma. Instituto Superior de Ciencias Agropecuarias de La Habana (ISCAH), Cuba. $67 \mathrm{p}$.

Cevallos, M. 2000. Establecimiento de una metodología eficiente en el proceso de embriogénesis somática del cafeto. Tesis presentada en opción al grado de Doctor en Ciencias. Instituto Nacional de Ciencias Agrícolas (INCA), La Habana, Cuba.186 p.

De Feria, M; Jiménez, E; Quiala, E; Barbón, R; Capote, A. 2003. Effect of disolved oxygen concentration on differentiation of somatic embryos of Coffea arabica cv. Catimos 9722. Plant Cell, Tissue and Organ Culture, 72:1-6.

Díaz, W; Molina, G; Vásquez, E; Reyes, R. 2002. Comportamiento morfológico y rendimientos en la primera cosecha de cafetos (Coffea canephora Pierre) plantados bajo cuatro densidades. Café Cacao 3(3):26-28.

FAO (Food and Agricultural Organization). 2000. Año internacional de las montañas (documentos de conceptos). Roma, Italia. 28 p. 
García, D; Rojas, R; Martínez, M; Cuba, M. 1996. Métodos para la evaluación del crecimiento de suspensiones celulares de Coffea canephora variedad Robusta. Cultivos Tropicales 17(1):85-87.

González, ME; Hernández, MM; Hernández, A. 2007. Comportamiento de diferentes genotipos de cafeto frente al empleo de un biopreparado bacteriano en la callogénesis. Cultivos Tropicales 28(3):39-45.

Hernández, A. 2002. Obtención de un biopreparado a partir de rizobacterias asociadas al cultivo del maíz (Zea mays L.). Tesis de Doctorado en Ciencias Biológicas. Universidad de la Habana (UH). La Habana, Cuba. 104 p.

INCA. START. 1998. Sistema automático para Análisis Estadístico, (Versión 4.10, 1998), disco compacto, 8 mm. La Habana, Cuba.

Jong, AJ; Heidstra, R; Spaink, HP; Hartog, M; Meijer, E; Hendriks, T; Lo Schiavo, F; Bisseling, T; Van Kammen, A; De Vries, SC. 1993. Rhizobium oligosacharides rescue a carrot somatic embryo mutant. Plant Cell 2:615-620.

Klimaszewska, K; Trointin, F; Becwar, M; Devillard, C; Park, Y; Lelu-Walter, L. 2007. Recent progress in Somatic embryogenesis of four Pinus spp. Tree and Forestry Science and Biotechnology 1(1):11-25.

López, C; Cabrera, M; Silva, N; Carracedo, C; Pérez, P; Sánchez, C. 1993. Algunos aspectos productivos de Coffea canephora ex Froehner. Rev. Baracoa 3(2):60-67.

Montagnon, C; Leroy, T; Eskes, AB. 1998. Varietal improvement of Coffea canephora. II - Breeding programmes and their results. Plantation Recherche Developpement 5:89-98.

Montes, S; Martínez M; Rojas R; Santana N; Cuba, M. 1995. Obtención de embriones somáticos a partir de suspensiones celulares de Coffea canephora var. Robusta. Cultivos Tropicales 16(3):77-81.

Murashige, T; Skoog, F. 1962. A revised medium for rapid growth and bioassoys whith tobbaco tissue cultures. Physiology Plants 15:473-497.
Ricketts, T; Daily, G; Ehrlich, P; Michener, C. 2004. Economic value of tropical forest to coffee production. Proc. of National Academy of Sciences 101(34): 12570-12582.

Salazar, Y; Hoyos, R. 2007. Multiplicación y tuberización in vitro de ñame (Dioscorea alata L.) en sistema de inmersión temporal. Rev. Fac. Nac. Agr. Medellín 60 (2):3907-3921.

Sánchez, L. 2006. Tercer Simposio Internacional de Café y Cacao: Reconquista productiva. Santiago de Cuba, Cuba. Periódico Sierra Maestra, Versión Digital. 1 p.

Santana, N; Martínez, O; González, MC. 1998. Embriogénesis somática en el cultivo del café (Coffea arabica) (Parte I). Cultivos Tropicales 10:36-43.

Shapiro, SS; Francia, RS. 1972. An approximate analysis of variance test for normality. Journal of the American Statistical Association 67:215-216.

Statistical Graphics Corp. 1999. STAGRAPHICS Plus por Windows 4.1. Disco compacto, $8 \mathrm{~mm}$. La Habana, Cuba.

Van Boxtel, J; Berthouly, M. 1996. High frequency somatic embryogenesis from coffee leaves factors influencing embryogenesis and subsequent proliferation and regeneration in liquid medium. Plant Cell Tissue and Orga Culture 44:7-17.

Zamarripa, CA; Ducos, JP; Tessereau, H; Bollon, H; Petiard, V. 1991.Production d' embryons somatiques de cafeier en milieu liquide: Effets densite d' inoculación et renouvellement du milieu. Café, Cacao, Thé 35(4): 21-26.

Zamarripa, CA. 1993. Etude et développement de l'embryogenése somatique en milieu liquide du caféier (Coffea canephora P., Coffea arabica L. et l'hybride Arabusta). These présentée devant: L'Ecole National Superire Agronomique de rennes pour obtenir le titre de Docteur de L'ensar. Préparéedan le Centre de Biotechnologie Vegétale Francerero. 191 p. 